\title{
VIEWPOINT
}

\section{Frailty in the critically ill: a novel concept}

\author{
Robert C McDermid', Henry T Stelfox² and Sean M Bagshaw**
}

\begin{abstract}
The concept of frailty has been defined as a multidimensional syndrome characterized by the loss of physical and cognitive reserve that predisposes to the accumulation of deficits and increased vulnerability to adverse events. Frailty is strongly correlated with age, and overlaps with and extends aspects of a patient's disability status (that is, functional limitation) and/ or burden of comorbid disease. The frail phenotype has more specifically been characterized by adverse changes to a patient's mobility, muscle mass, nutritional status, strength and endurance. We contend that, in selected circumstances, the critically ill patient may be analogous to the frail geriatric patient. The prevalence of frailty amongst critically ill patients is currently unknown; however, it is probably increasing, based on data showing that the utilization of intensive care unit (ICU) resources by older people is rising. Owing to the theoretical similarities in frailty between geriatric and critically ill patients, this concept may have clinical relevance and may be predictive of outcomes, along with showing important interaction with several factors including illness severity, comorbid disease, and the social and structural environment. We believe studies of frailty in critically ill patients are needed to evaluate how it correlates with outcomes such as survival and quality of life, and how it relates to resource utilization, such as length of mechanical ventilation, ICU stay and duration of hospitalization. We hypothesize that the objective measurement of frailty may provide additional support and reinforcement to clinicians confronted with endof-life decisions on the appropriateness of ICU support and/or withholding of life-sustaining therapies.
\end{abstract}

\section{What is frailty?}

Gerontologists have defined frailty as a multi-dimensional syndrome characterized by the loss of physical and cognitive reserve that leads to increased vulnerability to

*Correspondence: bagshaw@ualberta.ca

'Division of Critical Care Medicine, Faculty of Medicine and Dentistry, University of Alberta, 3C1.12 Walter C Mackenzie Centre, 8440-112 ST NW, Edmonton, Canada T6G 2 B7

Full list of author information is available at the end of the article adverse events [1]. Frailty overlaps and extends beyond disability (functional limitation) and comorbidity (coexistence of two diseases), and acknowledges that patients can be disabled and/or have comorbidities without being frail, and vice versa.

Ageing is a complex interplay between genetics and environment that begins during embryonic and fetal development. The mechanisms underlying the ageing process are only beginning to be clarified. In recognizing that ageing is a very heterogeneous process, many clinicians seek a method to quantify physiologic age rather than simply chronologic age. Since frailty has been shown to closely correlate with the ageing process [2], it has been suggested that the syndrome of frailty may be just such a measure.

One hypothesis whereby ageing is associated with and may predispose to development of frailty relates to the concept of inflammaging: the dynamic interplay between the protective proinflammatory response to invading microorganisms and the similarly protective compensatory anti-inflammatory system, which defends against uncontrolled inflammation. Genetic polymorphisms in the proinflammatory and anti-inflammatory responses have been proposed as one potential mechanism to explain some of the individual variability in the rate of ageing, and may partly explain the poor discriminatory power of age alone to predict outcome [3]. An excessively strong proinflammatory response that may be protective during the reproductive years may become maladaptive later in life [4]. By exhausting the compensatory antiinflammatory system, the proinflammatory response results in unintended damage to the host organism and predisposes to a vicious cycle of decreasing muscle mass, malnutrition and reduced energy expenditure. This cycle eventually culminates in the inability to maintain homeostasis and an 'avalanche-like destruction of the organism' $[2,4]$. One expression of this unbridled inflammation may be the syndrome of frailty, a state in which physiologic deficits accumulate that individually may be reversible but collectively often represent an insurmountable burden of disease and consequently vulnerability to adverse outcomes [5] (Figure 1).

\section{Measuring and quantifying frailty}

The syndromic nature of frailty presents challenges in creating an effective definition of the state. As previously 


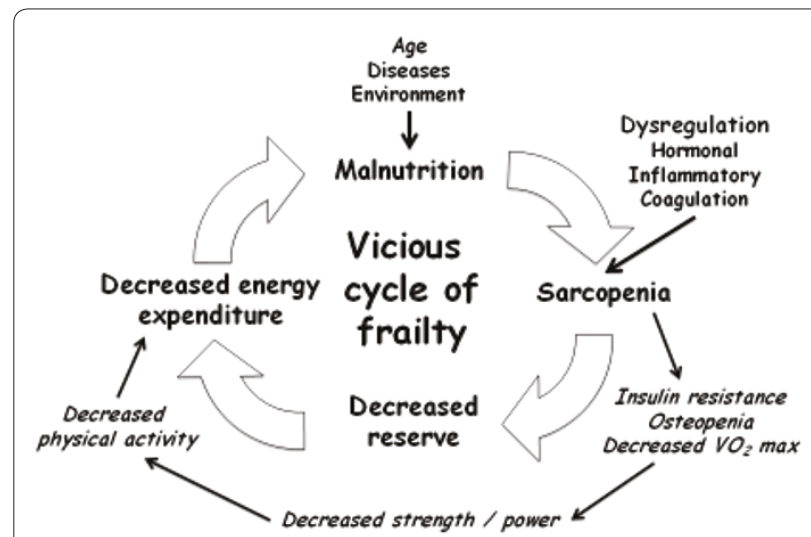

Figure 1. Overview of the vicious cycle of frailty. $\mathrm{VO}_{2}$ max, maximal oxygen consumption. Adapted from [2].

noted, frailty is strongly correlated with chronological age [6], but it is not an inevitable part of ageing [1]. Furthermore, the prevalence of frailty within closely aligned age strata, even in the very old person, is variable [7]. Consequently, a number of descriptive tools have been developed to define and quantify frailty.

One of the most widely adopted tools is the operational definition described by Fried and colleagues [2] (Table 1). The Frailty Index, a detailed 70-item inventory of clinical deficits, is also broadly used in studies of frailty [8]. A more generic, less detailed but no less clinically valid impression of patient frailty has also been developed by Rockwood and colleagues [1]. In 2,305 patients aged 65 years or older participating in the second stage of the Canadian Study on Health and Aging, Rockwood and colleagues developed and validated a judgment-based seven-point Clinical Frailty Scale (CFS) to measure frailty [1] (Table 2). In their study, the CFS was highly correlated with the Frailty Index. Participants with higher CFS scores were older, more often female, and more likely to have cognitive impairment and impaired mobility. By multi-variable analysis, each one-point increase in the CFS translated into significantly higher hazards of death (hazard ratio $=1.30$ ) and entry into an institutional facility (hazard ratio $=1.46$ ). Each of these tools appears to perform similarly well in identifying older patients at risk for adverse outcomes, but to date have not been evaluated in other populations $[1,2,9,10]$.

\section{How is frailty relevant to critical care?}

The prevalence of frailty in the older demographic may be as high as $43 \%[1,11]$. Based on evidence showing that utilization of intensive care unit (ICU) resources by older people is rising, the prevalence of pre-existing frailty in patients admitted to the ICU is probably also increasing [3].

The relevance of frailty, however, is not limited to admission demographics. Whether due to chronic
Table 1. Proposed clinical definition of the phenotype of frailty

Criteria
1. Decreased grip strength
2. Self-reported exhaustion
3. Unintentional weight loss of more than $4.5 \mathrm{~kg}$ over the past year
4. Slow walking speed
5. Low physical activity
Definition
Positive for frail phenotype: $\geq 3$ criteria present
Intermediate/pre-frail: one or two criteria present
Nonfrail: no criteria present

Adapted from Fried and colleagues [2].

disease depleting the reserve or acute disease overwhelming the reserve, the critically ill patient is vulnerable to adverse clinical outcomes, as evidenced by the number and severity of unexpected deteriorations in clinical status requiring increases in the degree of life support, without which the critically ill patient would die. Additionally, deficits associated with frailty, which typically take years to accumulate in the outpatient geriatric population, rapidly develop in a large proportion of critically ill patients independent of age and illness severity. These features include muscle wasting, clinically significant weakness and poor functional status following discharge from the ICU [12,13]. A recent editorial underscored the potential importance of inflammation in the development of acquired muscle weakness in the critically ill patient [14]. Additional pathophysiologic mechanisms proposed for these findings have included immobilization, suboptimal nutritional supplementation and ineffective substrate utilization - all of which may be further compounded by medications such as neuromuscular blockers and corticosteroids [15]. In fact, functional dependence after critical illness is correlated with two of the phenotypic features of characterizing frailty: inability to walk and poor upper extremity strength [13].

Since critically ill patients of all ages may share many of the features seen in frail geriatric patients, we contend that the concept and measurement of frailty may have clinical, psychosocial and economic relevance to critical care medicine. Accordingly, we hypothesize that the objective evaluation of frailty in critical illness may complement and/or contribute important prognostic information in the clinical care of patients.

\section{What are the prognostic implications of frailty?}

Frailty is recognized as a major determinant of mortality, hospitalization, institutionalization and functional outcome in geriatric patients, and outperforms chronological 
Table 2. Clinical Frailty Score

\begin{tabular}{|c|c|c|}
\hline Score & Frailty grade & Description \\
\hline 1 & Very fit & $\begin{array}{l}\text { People who are robust, active, energetic and motivated. These people commonly exercise regularly. They are among the } \\
\text { fittest for their age. }\end{array}$ \\
\hline 2 & Well & $\begin{array}{l}\text { People who have no active disease symptoms but are less fit than those of category 1. Often, they exercise or are very } \\
\text { active occasionally (that is, seasonally). }\end{array}$ \\
\hline 3 & Managing well & People whose medical problems are well controlled, but are not regularly active beyond routinely walking. \\
\hline 4 & Vulnerable & $\begin{array}{l}\text { While not dependent on other for daily help, symptoms often limit activities. A common complaint is being slowed up, } \\
\text { and/or being tired during the day. }\end{array}$ \\
\hline 5 & Mildly frail & $\begin{array}{l}\text { These people often have more evident slowing, and need help in high-order independent activities of daily living } \\
\text { (finances, transportation, heavy housework, medications). Typically, mild frailty progressively impairs shopping and } \\
\text { walking outside alone, meal preparation and housework. }\end{array}$ \\
\hline 6 & Moderately frail & $\begin{array}{l}\text { People need help with all outside activities and with keeping house. Inside, they often have problems with stairs and need } \\
\text { help with bathing and might need minimal assistance (cuing, standby) with dressing. }\end{array}$ \\
\hline 7 & Severely frail & $\begin{array}{l}\text { Completely dependent for personal care, from whatever cause (physical or cognitive). Even so, they seem stable and not } \\
\text { at high risk of dying (within } \sim 6 \text { months) }\end{array}$ \\
\hline 8 & Very severely frail & Completely dependent, approaching the end of life. Typically, they could not recover even from a minor illness. \\
\hline 9 & Terminally ill & $\begin{array}{l}\text { Approaching the end of life. This category applied to people with a life expectancy }<6 \text { months, who are not otherwise } \\
\text { evidently frail. }\end{array}$ \\
\hline
\end{tabular}

Adapted from Rockwood and colleagues [1].

age $[6,16,17]$. In fact, frailty may represent a surrogate for many of the difficult-to-measure aspects of a patient's prehospital health state. To date, however, no study has prospectively evaluated the prevalence or associated outcomes of frailty in critically ill patients.

Traditionally, prognostication in critical illness has relied heavily upon measures of acute physiologic derangements present at or within 24 hours of ICU admission - that is, Acute Physiology and Chronic Health Evaluation II [18], Sequential Organ Failure Assessment [19], Simplified Acute Physiology Score II [20] - and has modeled illness severity to the estimate probability of survival [21-23]. These scoring systems incorporate a limited assessment of sociodemographic characteristics (that is, age, social support, education and comorbidity) and do not integrate any significant measures of prehospital functional status, scope or severity of comorbid illness, disability or frailty. Addressing these limitations is particularly important when considering long-term outcomes (that is, 6 or 12 months) following critical illness. The increasing recognition of poor intermediate and long-term outcomes of critical illness - including not only survival, but also functional status, institutionalization and quality of life - coupled with the huge financial cost of critical care therapy means that better tools to predict those patients who will benefit most from critical care treatment are urgently needed [24].

There is increasing evidence to suggest that physiologic reserve may be an important determinant of clinical outcome in critically ill patients and that baseline functional status and the burden of pre-existing comorbid illness have prognostic value [18,25-28]. We currently have no method, however, to estimate this physiologic reserve or capacity to heal in critically ill patients. Moreover, when considering the increasing age and complexity of patients admitted to the ICU, advances in life-support technology and changing societal expectations for recovery, accurate prognostication in the ICU becomes very emotionally charged and challenging [11].

A prospective multi-center study of 980 survivors of critical illness found recently that pre-existing comorbid disease was the strongest predictor of post-ICU quality of life [28]. Additionally, simple measures of burden of preexisting disease and global function, such as residency in a nursing home facility, have also been shown to correlate with mortality [29]. Frailty explicitly captures this sort of functional dependence in an easily comprehensible and more descriptive fashion, but has not yet been evaluated in the critically ill patient. Owing to the potential similarities in frailty between geriatric patients and critically ill patients, the concept of frailty in critical illness may have clinical relevance, be independently predictive of outcomes and show interaction with several factors, including illness severity, comorbid illness, and the social and structural environment. We contend that studies of frailty in critically ill patients are needed to evaluate how frailty correlates with clinical outcomes such as survival and quality of life, but also how frailty correlates with resource utilization, such as lengths of mechanical ventilation, ICU stay and duration of hospitalization. We also believe that if frailty is proven to have clinical and prognostic relevance, its objective measurement may provide additional support and 
reinforcement to critical care clinicians engaged in goals of care planning and/or end-of-life decisions [11].

\section{How might we quantify frailty in the critically ill patient?}

Time constraints necessitate a tool that is simple to understand and easy to administer rapidly, if the tool is to be used clinically on admission to the ICU. Furthermore, the required information must be obtainable from friends and family, as the patient is often unable to participate in the assessment in an active way. These make the commonly-used operational definition of Fried and colleagues difficult to apply. The Frailty Index is also difficult to incorporate into a busy critical care practice, as the degree of detail required makes the tool cumbersome and time consuming to use. On the other hand, the CFS is readily available at the bedside and is easier to understand and use than other frailty assessment tools. Consequently, the CFS may be the optimal tool for use on admission to the ICU. Furthermore, while the CFS is judgment based and has some subjectivity, it captures a spectrum of information that transcends several aspects of a patient's premorbid health state. This flexibility is also likely to be advantageous and has been validated in other clinical settings $[1,30]$. The CFS has now been adapted and validated for administration by health research coordinators and by telephone interview, making it practically useful in the critical care setting where obtaining collateral history from family members and friends is an integral part of the informationgathering process [31].

Recognizing that frailty is not a static state, evaluating the patient for frailty in the recent past and quantification of developing frailty during hospitalization in the ICU may also add considerable predictive power to the assessment. In addition to quantifying admission frailty, obtaining a historical point estimate of frailty by retrospectively administering the CFS through friends and family regarding function in the recent past could create an estimate of premorbid health trajectory. Additionally, by tracking features related to Fried's operational definition of frailty during the ICU stay (such as weight, nitrogen balance, adequacy of caloric supplementation, walking distance, upper extremity strength and selfreported exhaustion), one may be able to create an objective measure of healing that to date is limited to serial administration of admission prognostic scores [14]. Such an assessment that includes both premorbid trajectory and response to critical care intervention would be very useful both for physicians with respect to individualization of prognosis and for families during end-of-life discussions, by providing objective, easily comprehensible critical care benchmarks for response to treatment.

\section{Are there therapeutic implications for frailty?}

Previous studies looking at multi-dimensional interventions to prevent adverse events in older patients have shown promise [32,33]; patient deterioration after the completion of the trial was common, however, and inferences may have been limited due to lack of an agreedupon definition for frailty. Recognition of the multifaceted nature of frailty has recently led to investigation of multi-dimensional home-based interventions intended to interrupt the vicious cycle of frailty. In the ongoing British Frailty Intervention Trial, individualized nutritional, social, psychological and physical interventions targeted at frailty are being evaluated in a group of older adults who are considered frail by the operational definition proposed by Fried and colleagues [2,34]. These interventions include nutritional intake analysis, home meal delivery and high-calorie/high-protein meal supplementation, day activity groups, psychiatric referral and home physiotherapy. It is hoped that this multi-faceted approach in a validated high-risk frail patient population will be effective.

Similarly, the importance of adequate nutritional support [35], the value of sedation interruption [36] coupled with early mobilization [37] and physiotherapy [38] to prevent physical deconditioning, and the psychological consequences of critical illness for both patients and their caregivers [39] are being increasingly recognized in the ICU setting. Since single interventions have historically had limited success in altering critical care outcomes with a few notable exceptions [40-42], a more effective approach may be to stratify critically ill patients based on frailty and intervene in a similarly-styled multidisciplinary way that targets multiple facets of the vicious cycle of frailty. It is conceivable that the preexisting and/or newly developing frailty modifies the potential attributable benefit of timely and effective acute physiologic support in the critically ill patient. Accordingly, we hypothesize that a better characterization of pre-existing frailty and its ongoing development may represent a novel method for risk identification and stratification for future clinical and therapeutic interventions in critical illness.

\section{Conclusion}

Frailty is common in geriatric populations and has shown clear association with risk of death and institutionalization. The burden and potential modifying impact of frailty on the course and outcomes in critically ill patients is unknown. Although not yet clearly established in the ICU population, we believe that frailty has clinical relevance and may predict both short-term and longterm outcomes. The validation of available frailty instruments, such as the CFS, in critical care settings would be an important first step. 
If the measures of frailty are proven to have compelling prognostic value, such evidence could then be used for risk identification for novel therapeutic interventions or could potentially be integrated into clinical decisionmaking - not only at the bedside, but also at a health policy/societal level. Similarly, the inclusion of measures of frailty into cost-utility analyses would aid in identifying subgroups of ICU patients for whom the ICU would be least likely to preserve quality-adjusted survival and/or functional independence. Furthermore, therapeutic strategies in the ICU designed to minimize the development and consequences of frailty may have significant beneficial effects on utilization, cost and effectiveness of ICU support.

Until recently, the main thrust of critical care diagnosis and management has been on the acute processes leading to homeostatic imbalance. A paradigm that includes a better understanding of frailty may cause a fundamental shift of focus, with the diagnosis, treatment and prevention of frailty being considered equally as important as acute physiologic support for critical illness.

\section{Abbreviations}

CFS, Clinical Frailty Scale; ICU, intensive care unit.

\section{Competing interests}

The authors declare that they have no competing interests.

\section{Acknowledgements}

SMB is supported by a Clinical Investigator Award from the Alberta Heritage Foundation for Medical Research.

\section{Author details}

'Division of Critical Care Medicine, Faculty of Medicine and Dentistry, University of Alberta, 3C1.12 Walter C Mackenzie Centre, 8440-112 ST NW, Edmonton, Canada T6G 2B7. ${ }^{2}$ Department of Critical Care Medicine, Faculty of Medicine, University of Calgary, Foothills Medical Centre, Room 1105, South Tower, 1403-29 ${ }^{\text {th }}$ ST NW, Calgary, Canada, T2N 2T9.

Published: 4 February 2011

\section{References}

1. Rockwood K, Song X, MacKnight C, Bergman H, Hogan DB, McDowell I, Mitnitski A: A global clinical measure of fitness and frailty in elderly people. CMAJ 2005, 173:489-495.

2. Fried LP, Tangen CM, Walston J, Newman AB, Hirsch C, Gottdiener J, Seeman T, Tracy R, Kop WJ, Burke G, McBurnie MA: Frailty in older adults: evidence for a phenotype. J Gerontol A Biol Sci Med Sci 2001, 56:M146-M156.

3. Bagshaw SM, Webb SA, Delaney A, George C, Pilcher D, Hart GK, Bellomo R: Very old patients admitted to intensive care in Australia and New Zealand: a multi-centre cohort analysis. Crit Care 2009, 13:R45.

4. Franceschi C, Capri M, Monti D, Giunta S, Olivieri F, Sevini F, Panourgia MP, Invidia L, Celani L, Scurti M, Cevenini E, Castellani GC, Salvioli S: Inflammaging and anti-inflammaging: a systemic perspective on aging and longevity emerged from studies in humans. Mech Ageing Dev 2007, 128:92-105.

5. Lunney JR, Lynn J, Foley DJ, Lipson S, Guralnik JM: Patterns of functional decline at the end of life. JAMA 2003, 289:2387-2392.

6. Mitnitski AB, Graham JE, Mogilner AJ, Rockwood K: Frailty, fitness and latelife mortality in relation to chronological and biological age. BMC Geriatr 2002, 2:1.

7. Rockwood K, Mogilner A, Mitnitski A: Changes with age in the distribution of a frailty index. Mech Ageing Dev 2004, 125:517-519.

8. Rockwood K, Andrew M, Mitnitski A: A comparison of two approaches to measuring frailty in elderly people. J Gerontol A Biol Sci Med Sci 2007 62:738-743.
9. Fried LP, Ferrucci L, Darer J, Williamson JD, Anderson G: Untangling the concepts of disability, frailty, and comorbidity: implications for improved targeting and care. J Gerontol A Biol Sci Med Sci 2004, 59:255-263.

10. Rockwood K, Mitnitski A, Macknight C: Some mathematical models of frailty and their clinical implications. Rev Clin Gerontol 2002, 12:109-117.

11. MCDermid RC, Bagshaw SM: Prolonging life and delaying death: the role of physicians in the context of limited intensive care resources. Philos Ethics Humanit Med 2009, 4:3.

12. De Jonghe B, Sharshar T, Lefaucheur JP, Authier FJ, Durand-Zaleski I, Boussarsar M, Cerf C, Renaud E, Mesrati F, Carlet J, Raphael JC, Outin H, Bastuji-Garin S: Paresis acquired in the intensive care unit: a prospective multicenter study. JAMA 2002, 288:2859-2867.

13. van der Schaaf M, Dettling DS, Beelen A, Lucas C, Dongelmans DA, Nollet F: Poor functional status immediately after discharge from an intensive care unit. Disabil Rehabil 2008, 30:1812-1818.

14. Winkelman C: The role of inflammation in ICU-acquired weakness. Crit Care 2010, 14:186.

15. Griffiths RD, Hall JB: Intensive care unit-acquired weakness. Crit Care Med 2010, 38:779-787.

16. Schuurmans H, Steverink N, Lindenberg S, Frieswijk N, Slaets JP: Old or frail: what tells us more? J Gerontol A Biol Sci Med Sci 2004, 59:M962-M965.

17. Mitnitski AB, Mogilner AJ, MacKnight C, Rockwood K: The mortality rate as a function of accumulated deficits in a frailty index. Mech Ageing Dev 2002 123:1457-1460.

18. Ho KM, Finn J, Knuiman M, Webb SA: Combining multiple comorbidities with Acute Physiology Score to predict hospital mortality of critically ill patients: a linked data cohort study. Anaesthesia 2007, 62:1095-1100.

19. Ferreira FL, Bota DP, Bross A, Melot C, Vincent JL: Serial evaluation of the SOFA score to predict outcome in critically ill patients. JAMA 2001, 286:1754-1758.

20. Delle Karth G, Meyer B, Bauer S, Nikfardjam M, Heinz G: Outcome and functional capacity after prolonged intensive care unit stay. Wien Klin Wochenschr 2006, 118:390-396.

21. Le Gall JR, Lemeshow S, Saulnier F: A new Simplified Acute Physiology Score (SAPS II) based on a European/North American multicenter study. JAMA 1993, 270:2957-2963.

22. Knaus WA, Draper EA, Wagner DP, Zimmerman JE: APACHE II: a severity of disease classification system. Crit Care Med 1985, 13:818-829.

23. Vincent JL, Moreno R, Takala J, Willatts S, De Mendonca A, Bruining H, Reinhart CK, Suter PM, Thijs LG: The SOFA (Sepsis-related Organ Failure Assessment) score to describe organ dysfunction/failure. On behalf of the Working Group on Sepsis-Related Problems of the European Society of Intensive Care Medicine. Intensive Care Med 1996, 22:707-710.

24. Unroe M, Kahn JM, Carson SS, Govert JA, Martinu T, Sathy SJ, Clay AS, Chia J, Gray A, Tulsky JA, Cox CE: One-year trajectories of care and resource utilization for recipients of prolonged mechanical ventilation: a cohort study. Ann Intern Med 2010, 153:167-175.

25. Dowdy DW, Eid MP, Sedrakyan A, Mendez-Tellez PA, Pronovost PJ, Herridge MS, Needham DM: Quality of life in adult survivors of critical illness: a systematic review of the literature. Intensive Care Med 2005, 31:611-620.

26. Poses RM, McClish DK, Smith WR, Bekes C, Scott WE: Prediction of survival of critically ill patients by admission comorbidity. J Clin Epidemio/ 1996, 49:743-747.

27. Vazquez Mata G, Rivera Fernandez R, Gonzalez Carmona A, DelgadoRodriguez M, Torres Ruiz JM, Raya Pugnaire A, Aguayo de Hoyos E: Factors related to quality of life 12 months after discharge from an intensive care unit. Crit Care Med 1992, 20:1257-1262.

28. Orwelius L, Nordlund A, Nordlund P, Simonsson E, Backman C, Samuelsson A Sjoberg F: Pre-existing disease: the most important factor for health related quality of life long-term after critical illness: a prospective, longitudinal, multicentre trial. Crit Care 2010, 14:R67.

29. Kothe H, Bauer T, Marre R, Suttorp N, Welte T, Dalhoff K: Outcome of community-acquired pneumonia: influence of age, residence status and antimicrobial treatment. Eur Respir J 2008, 32:139-146.

30. Charlson ME, Hollenberg JP, Hou J, Cooper M, Pochapin M, Pecker M: Realizing the potential of clinical judgment: a real-time strategy for predicting outcomes and cost for medical inpatients. Am J Med 2000, 109:189-195.

31. Chan DC, Tsou HH, Chen CY: Validation of the Chinese-Canadian study of health and aging clinical frailty scale (CSHA-CFS) telephone version. Arch Gerontol Geriatr 2010, 50:e74-e80. 
32. Beswick AD, Rees K, Dieppe P, Ayis S, Gooberman-Hill R, Horwood J, Ebrahim $\mathrm{S}$ : Complex interventions to improve physical function and maintain independent living in elderly people: a systematic review and metaanalysis. Lancet 2008, 371:725-735.

33. Gill TM, Baker DI, Gottschalk M, Peduzzi PN, Allore H, Byers A: A program to prevent functional decline in physically frail, elderly persons who live at home. N Engl J Med 2002, 347:1068-1074.

34. Fairhall N, Aggar C, Kurrle SE, Sherrington C, Lord S, Lockwood K, Monaghan N, Cameron ID: Frailty Intervention Trial (FIT). BMC Geriatr 2008, 8:27.

35. Doig GS, Simpson F, Finfer S, Delaney A, Davies AR, Mitchell I, Dobb G: Effect of evidence-based feeding guidelines on mortality of critically ill adults: a cluster randomized controlled trial. JAMA 2008, 300:2731-2741.

36. Schweickert WD, Pohlman MC, Pohlman AS, Nigos C, Pawlik AJ, Esbrook CL, Spears L, Miller M, Franczyk M, Deprizio D, Schmidt GA, Bowman A, Barr R, McCallister KE, Hall JB, Kress JP: Early physical and occupational therapy in mechanically ventilated, critically ill patients: a randomised controlled trial. Lancet 2009, 373:1874-1882.

37. Kress JP: Clinical trials of early mobilization of critically ill patients. Crit Care Med 2009, 37(10 Suppl):S442-S447.

38. Salisbury LG, Merriweather JL, Walsh TS: The development and feasibility of a ward-based physiotherapy and nutritional rehabilitation package for people experiencing critical illness. Clin Rehabil 2010, 24:489-500.
39. Davydow DS, Gifford JM, Desai SV, Bienvenu OJ, Needham DM: Depression in general intensive care unit survivors: a systematic review. Intensive Care Med 2009, 35:796-809.

40. ARDS Network: Ventilation with lower tidal volumes as compared with traditional tidal volumes for acute lung injury and the acute respiratory distress syndrome. The Acute Respiratory Distress Syndrome Network. NEngl J Med 2000, 342:1301-1308.

41. Bernard GR, Vincent JL, Laterre PF, LaRosa SP, Dhainaut JF, Lopez-Rodriguez A Steingrub JS, Garber GE, Helterbrand JD, Ely EW, Fisher CJ Jr: Efficacy and safety of recombinant human activated protein C for severe sepsis. N Engl J Med 2001, 344:699-709.

42. Rivers E, Nguyen B, Havstad S, Ressler J, Muzzin A, Knoblich B, Peterson E, Tomlanovich M: Early goal-directed therapy in the treatment of severe sepsis and septic shock. N Engl J Med 2001, 345:1368-1377.

doi:10.1186/cc9297

Cite this article as: McDermid RC, et al:: Frailty in the critically ill: a novel concept. Critical Care 2011, 15:301. 